\title{
Stopping and Range of lons in Matter data for polymeric materials simulating the process of plasma immersion íon implantation
}

\section{Dados de parada e intervalo de íons na matéria para materiais poliméricos simulando o processo de implantação iônica por imersão em plasma}

Péricles Lopes Sant’Ana1*, José Roberto Ribeiro Bortoleto ${ }^{1}$ Nilson Cristino da Cruz¹, Elidiane Cipriano Rangel ${ }^{1}$, Steven Frederick Durrant ${ }^{1}$

\begin{abstract}
This work introduces the physicochemical surface properties of three commercial polymers: white polyvinyl chloride (PVC), polyethylene terephthalate (PET), and low-density polyethylene (LDPE) as results of plasma immersion ion implantation (PIII) using SF6 and N2 plasmas at low-pressure vacuum system. For comparison, SRIM calculations/ were used to access the following output data: ion range and distribution (screening a Gaussian histogram); number of backscattered ions nB; and vacancies produced nV according to Kinchin-Pease formalism. In both approaches (experimental and simulated), it was used as inputting data: the main ion implantation parameter: $-1000 \mathrm{~V}$ of high-voltage negative pulses in PIII experiments which are matched to $1 \mathrm{keV}$ of input energy data in the virtual SRIM environment using $\mathrm{F}+$ and $\mathrm{N}+$ as projectiles ions, rigid PVC, PET mylar and LDPE marlex as targets. The purpose was to associate the surface properties of the polymeric samples obtained in laboratory by PIII technique. SRIM results pointed: a low random scattering and penetration of ions in low fluency distributed in the polymeric matrix, owing to inelastic collisions, which the ranged from 0 to $350 \mathrm{~nm}$ of depth on target materials.
\end{abstract}

Keywords: Plasma immersion ion implantation, SRIM (Stopping and Range of lons in Matter), Irradiated polymers.

\section{RESUMO}

Este trabalho apresenta as propriedades físico-químicas da superfície de três polímeros comerciais: cloreto de polivinil branco (PVC), tereftalato de polietileno (PET) e polietileno de baixa densidade (PEBD), como resultado da implantação iônica por imersão em plasma (IIIP) usando plasmas de SF6 e N2 em um sistema de vácuo de baixa pressão. Para comparação, os cálculos de SRIM foram usados para acessar os seguintes dados de saída: faixa e distribuição de íons (associado a um histograma gaussiano); número de íons retroespalhados nB; e vacâncias produzidas, NV, de acordo com o formalismo de Kinchin-Pease. Em ambas as abordagens (experimental e simulada), foram utilizados como dados de entrada: o principal parâmetro de implantação de íons: -1000 V de pulsos negativos de alta tensão em experimentos IIIP que correspondem a 1 keV de dados de energia de entrada no ambiente virtual SRIM usando F+ e N+ como íons de projéteis, PVC rígido, PET mylar e LDPE marlex como alvos. O objetivo foi associar as propriedades da superfície das amostras poliméricas obtidas em laboratório pela técnica IIIP. Resultados do SRIM apontaram: baixa dispersão e penetração aleatória de íons em baixa fluência distribuída na matriz polimérica, devido a colisões inelásticas, que variaram de 0 a 350 $\mathrm{nm}$ de profundidade dos materiais alvo.

Palavras-chave: Implantação lônica por Imersão em Plasma, Parada e intervalo de íons na matéria, polímeros irradiados. 


\section{INTRODUCTION}

In the past, radiation effects in polymeric materials were the domain of radiation chemistry, namely to the study of radiolysis and polymerization mechanisms induced by electron beams or $\gamma$-rays ${ }^{1,2}$, and several promising results with ion beam modification on polymeric materials are reported ${ }^{3}$. Nowadays the extensive dependence on polymeric materials drives considerably scientific and engineering efforts devoted to the discovery, development, and modifications of these materials ${ }^{4}$.

Among the technological methods used nowadays in commercial polymers, plasma surface treatment or deposition features some major advantages; they are fast and economical processes performed at room temperature, capable of treating complex shapes while they modify only the surface of the polymer leaving the bulk properties largely unaffected ${ }^{5,6}$. Techniques that allow selective surface modification have attracted the attention of many researches. Ion beam and, more recently, the plasma immersion ion implantation technique (PIII) have been applied to this purpose. The PIII technique ${ }^{7}$ has emerged as a powerful tool in virtue of its simplicity and effectiveness, and can be applied for a wide number of materials ${ }^{8,9}$.

The growing interest in ion-implanted polymeric materials is due to their increasing demand in various disciplines such as optical waveguides, nanocomposites, in satellites as shielding materials, for annealing effects, space crafts, semiconductors, and high-energy particle accelerators ${ }^{10-11}$. In this sense the introduction of new technologies could lead to a reduction in processing time or an improvement in operating conditions, thereby decreasing both environmental and financial costs ${ }^{12}$. The study of their properties is important for new and advanced technological fields like optoelectronics, microelectronics, automotive industry, filters, electrochemical sensors and medicine $e^{13-15}$.

\section{Effect of plasma action (ion bombardment) in polymeric materials}

An understanding of the ion-beam polymer interaction mechanisms is discussed hereafter. The modifications caused in the polymeric materials by ion bombardment in plasma immersion ion implantation (PIII) process are presented in Fig. 1. They are irreversible in the structure of treated polymer and, consequently, in its superficial physicochemical properties ${ }^{16,17}$.

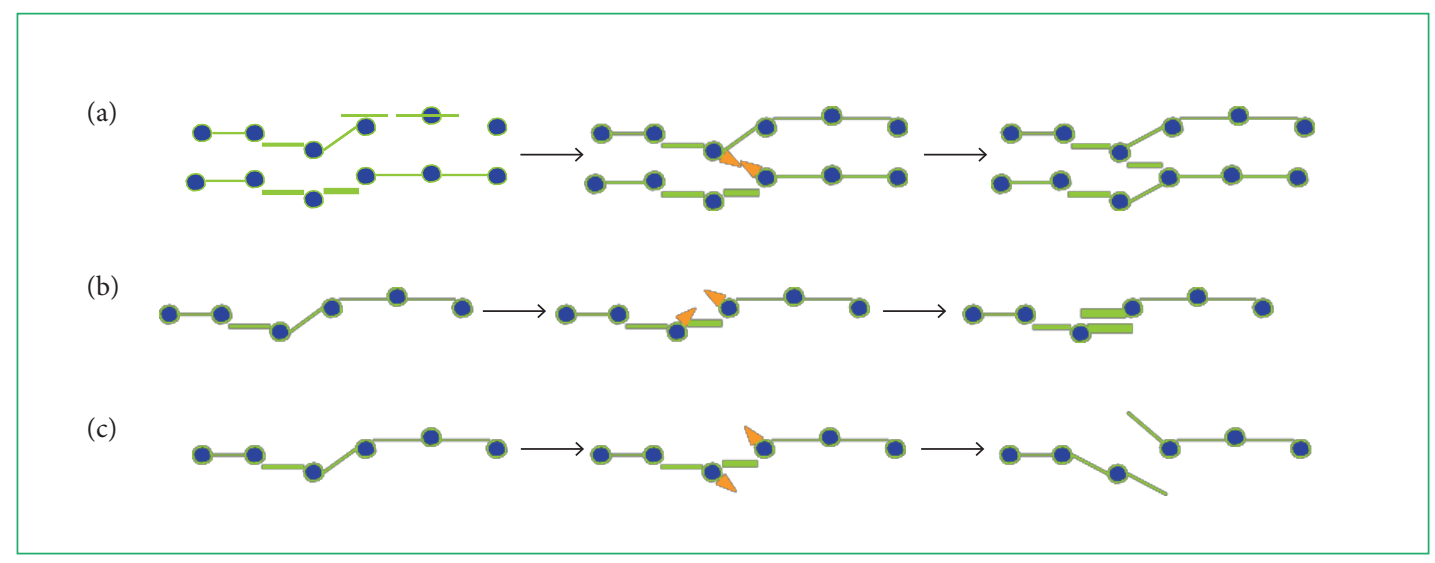

Figure 1: Plasma effect on polymeric chains due to ions bombardment. Electrons collision from the plasma ions to the backbone causes (a) cross-linked formation and (b) unsaturation. On the other hand, (c) nuclear collisions can dissociate polymeric chains, inducing volatile species that can be ejected by the vacuum pump.

Experimental results suggest that effective unsaturation can occur when ion pairs in two neighboring chains overlap ${ }^{18}$. Moreover, the structural transformations in ion beam-implanted polymers are based on chemical reactions of free radicals which appear as the result of dangling bonds and displaced target atoms (ions). Reactions occurring in irradiated polymers were considered in previous publications ${ }^{19}$. The stability of polymers under irradiation was greatly affected by the type of the chain-linking group and the type of pendent atoms or groups attached to the backbone carbon atoms. Depletion of volatile components and fragments, dynamic changes in the density of the implanted layer etc. may play a crucial role.

During the implantation, the polymer undergoes gradual compositional and structural changes and the resulting depth profile is in fact a sum of the depth distributions accumulated during various stages of the implantation process ${ }^{20}$. Among such properties, it was well established that physical and chemical properties change in polymers, and are determined by the magnitude of cross-linking and scission generated ${ }^{21}$. Moreover, the properties improvements were related to electronic energy transfer (excitation and ionization), and the degradation events (as a result of scission) by nuclear energy transfer (displacement reactions) $^{22}$. In this sense, it is important to explore the Stopping and Range of Ions in Matter (SRIM) simulation to analyze the damage events. 


\section{SRIM simulation}

Monte Carlo method is, in principle, a solution to a macroscopic system through simulation of its microscopic interactions. The code operates within the energy range from $100 \mathrm{eV}$ up to $1 \mathrm{GeV}$ and, for homogeneous materials, with arbitrary compositions (involving elements with atomic number $Z$ =1-92). The SRIM software treats the ion penetration in a material as a series of independent binary collisions. The only parameters used to describe a target material are the density of the material and the relative elemental composition ${ }^{23}$. The agreement between simulation and experiment is very good in the keV region.

The SRIM software provides information on the thickness of the modified layer determined by the penetration depth of the ions and their spatial distribution in the polymer matrix, as well as information on the statistical distribution ${ }^{24}$. In other study, SRIM was used for estimating a predicted thickness of implanted layers ${ }^{25}$ and vacancy distribution. In the "ion distribution and quick damage" mode, the defect numbers are estimated by using the Kinchin-Pease equation for each primary knock on atom based on its recoil energy ${ }^{26}$, and a phenomenological model based on equations from Lindhard, Scharff, Schiott (LSS) and Brandt-Kitagawa for electronic stopping ${ }^{27}$. The restriction is related to the fact that SRIM simulation does not take into account the compositional and structural changes of the polymer substrate in the course of the implantation. Moreover, the error in the energy absorbed by electrons collisions is set $\sim 0.05 \%$. For $1 \mathrm{keV}$ of ion beam, the loss is $\sim 1 \%$. As input, the program receives the type of substrate, which are the target material and the energies (in electronvolts) of the ions to be implanted.

In this work, positive ions are considered because, in practice, negative ions are repelled by the inferior electrode negatively polarized by PIII. The program, in turn, returns through a frequency histogram, the penetration depth of 99,999 incident ions projectile, and then electronic and nuclear collisions with the target substrate matrix are considered. In order to estimate the thickness of the modified layer for that energy after the collisions, being possible to observe in the histogram, the mean (most probable) range values, and the maximum depth value that ion can reach within the polymer lattice. The number of backscattered ions and vacancies can also be extracted.

\section{METHODS}

\section{Details of the laboratorial experiments}

After ultra-sonicated bath, the polymers substrates were led to the experimental setup of PIII processes from the Technological Plasmas Laboratory (LapTec). It consists of a stainless-steel vacuum chamber with two internal electrodes, separated by a distance of $5 \mathrm{~cm}$. Substrates were placed on the stainless steel electrode and the system was evacuated by a rotary pump (Edwards $\left.-18 \mathrm{~m}^{3} / \mathrm{h}\right)$ down to $10^{-1} \mathrm{~Pa}$. Needle valves (Edwards - model LV10K) were employed to control the gas feeding and a Barocel pressure sensor was used to monitor the chamber pressure. Sulfur hexafluoride $\left(\mathrm{SF}_{6}\right)$ and nitrogen $\left(\mathrm{N}_{2}\right)$ gases were employed as source of fluoride and inert plasma, respectively. Polyvinyl chloride (PVC) $\left[\Theta=74^{\circ} ; \mathrm{R}(\mathrm{z}) 4.4 \mathrm{~nm}\right]$, polyethylene terephthalate (PET) $\left[\Theta=66^{\circ} ; \mathrm{R}(\mathrm{z})=1.8 \mathrm{~nm} ; \mathrm{T}(\lambda) \sim 80 \%\right.$ at visible range $]$ and low density polyethylene $\left[\Theta=74^{\circ} ; \mathrm{R}(\mathrm{z})=42.7 \mathrm{~nm} ; \mathrm{T}(\lambda) \sim 75\right.$ to $80 \%$ at visible range] were directly exposed to the plasma environment established by the application of radiofrequency power (Tokyo Hi Power 13.56 MHz) coupled to a match in box circuit. The total pressure of the reactor was constant at $100 \mathrm{mTorr}(13.33 \mathrm{~Pa}$ ). The power applied was $25 \mathrm{~W}$ connected to the upper electrode while the low electrode was connected to high-voltage negative pulses at $-1000 \mathrm{~V}$ (corresponding to $1 \mathrm{keV}$ on the simulation data). The high voltage was generated by a source (GBS-Elektronic GmbH model RUP 6-20) monitored by a digital oscilloscope (Tektronix TDS 2014). The frequency was stable at $300 \mathrm{~Hz}$ while the cycle time was $30 \mu \mathrm{s}$. Temperature of treatment was maintained constant at $298 \mathrm{~K}$ and the treatment time was fixed at $300 \mathrm{~s}$.

\section{Stopping and Range of lons in Matter preparation and sampling}

The SRIM simulation was run considering the perpendicular incidence of: fluorine $[(\mathrm{F}+)$ mass $=18.998$ amu $]$ and nitrogen $\left[\left(\mathrm{N}^{+}\right)\right.$mass $\left.=14.003 \mathrm{amu}\right]$ ions on the polymeric targets with energies of 1 and $2.4 \mathrm{keV}$ (for comparison). Density values provided by the software were: rigid PVC density $\mathrm{r}=1.68 \mathrm{~g} / \mathrm{cm}^{3}$; PET (mylar) density $\mathrm{r}=1.397 \mathrm{~g} / \mathrm{cm}^{3}$; LDPE (marlex) density $\mathrm{r}$ $=0.93 \pm 0.3 \mathrm{~g} / \mathrm{cm}^{3}$. As input data was selected, ion distribution with recoils and quick calculation of damage mode, which provides a statistical estimated based on the Kinchin-Pease formalism28, which suggests that the number of point defects generated by an implanted ion is analytically derived from the energy that is transferred from an ion to an atom of the target material. It is assumed that the number of point defects generated by a primary recoil is proportional to the energy transferred from the ion to the primary recoil (for incident $\mathrm{E}<25 \mathrm{keV}$ ). In addition, targets containing $\mathrm{C}, \mathrm{H}, \mathrm{N}, \mathrm{O}$, F will need a compound correlation $(\sigma)$. This parameter is a correction to accounts for the effects of bonding changes and target bandgap.

Table 1 shows the information about the compound correlation, atomic density and proportion of atomic masses and number of atoms for the three polymeric targets according to the software database. 
Table 1: Atomic density ( $\rho \mathrm{a})$; compound correlation ( $\sigma)$; atomic mass proportion (\%) and number of atoms (\%) for the three polymeric targets according to SRIM 2008 database.
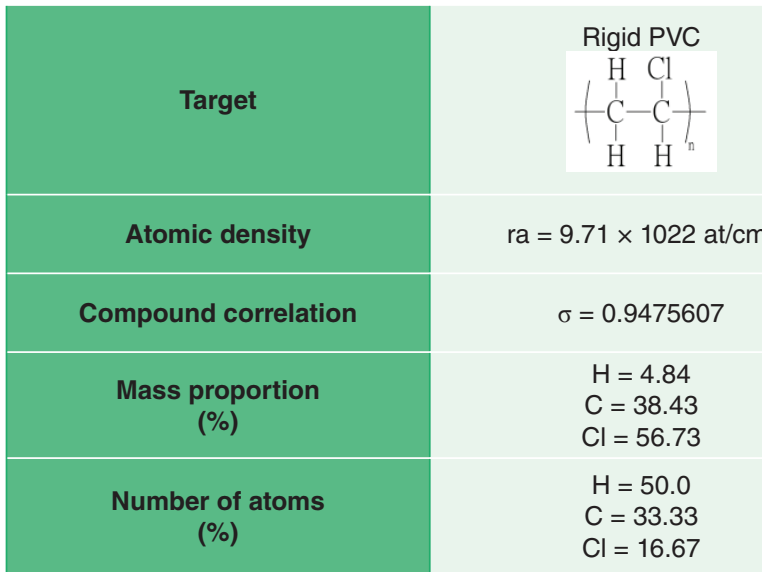

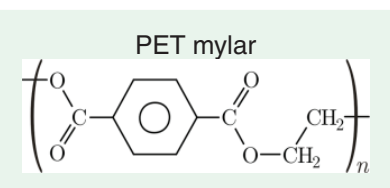

$\mathrm{ra}=9.63 \times 1022 \mathrm{at} / \mathrm{cm}^{3}$

$\sigma=0.9343234$

$\mathrm{H}=4.2$

$\mathrm{C}=62.5$

$\mathrm{O}=33.3$

$\mathrm{H}=36.36$

$\mathrm{C}=45.45$

$\mathrm{O}=18.18$

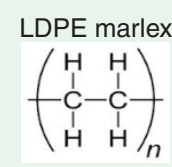

$r=1.2 \times 1023 \mathrm{at} / \mathrm{cm}^{3}$

$\sigma=1.0054160$

$\mathrm{H}=14.37$

$\mathrm{C}=85.63$

$\mathrm{H}=66.67$

$\mathrm{C}=33.33$

The compound correction is discussed in great details by Ziegler and Manoyan ${ }^{29}$. Despite the targets possess similar atomic density $\left(\sim 10^{22}\right.$ to $\left.10^{23} \mathrm{at} / \mathrm{cm}^{3}\right)$, Table 1 shows that the proportion of elements (\%) are different in mass and number of atoms for the targets. In PVC, chloride is present in less quantity (number of atoms); however, it represents higher proportion in mass, because its atomic mass unit $(\sim 35.4)$ is higher than carbon $(\sim 12.0)$ and hydrogen $(\sim 1.0)$. Analogously, hydrogen is present in the PET matrix in higher quantity (number of atoms) than oxygen; however, it represents lower proportion in mass, because its atomic mass unit is much lower than oxygen $(\sim 15.9 \mathrm{amu})$. Analogously, hydrogen is present in the LDPE matrix in higher quantity (number of atoms) than carbon; however, it represents lower proportion in mass, for the same reason.

\section{RESULTS}

\section{Ion ranges and distribution}

Table 2 synthesizes the results from the SRIM/TRIM simulation: Depth in ångström of incident ions $\left(\mathrm{F}^{+}\right)$, nitrogen $\left(\mathrm{N}^{+}\right)$for the three polymers targets, using the incident energies of 1 and $2.4 \mathrm{keV}$. The indexes (1) and (2) represents the range, mean and maximum values, respectively.

Table 2: Depth $(\AA)$ of incident fluorine ions $\left(\mathrm{F}^{+}\right)$and nitrogen $\left(\mathrm{N}^{+}\right)$for the three polymers investigated, using the incident energies of 1 and $2.4 \mathrm{keV}$. The indexes (1) and (2) represent the range, mean and maximum values, respectively.

\begin{tabular}{|c|c|c|c|c|}
\hline $\begin{array}{l}\text { Type of incident ion } \\
\text { projectile }\end{array}$ & $\begin{array}{c}\text { Initial energy } \\
\text { (keV) }\end{array}$ & $\begin{array}{c}\text { Range values of PVC } \\
\text { ions }(\AA) \\
r=1.30 \mathrm{~g} / \mathrm{cm} 3\end{array}$ & $\begin{array}{c}\text { Range values of PET } \\
\text { ions }(\AA) \\
r=1.39 \mathrm{~g} / \mathrm{cm} 3\end{array}$ & $\begin{array}{c}\text { Range values of LDPE } \\
\text { ions }(\AA) \\
r=0.93 \mathrm{~g} / \mathrm{cm} 3\end{array}$ \\
\hline \multirow[b]{2}{*}{$\mathrm{F}+$} & 1 & $\begin{array}{l}\text { (1) } 70 \\
\text { (2) } 175\end{array}$ & $\begin{array}{l}\text { (1) } 45 \\
\text { (2) } 125\end{array}$ & $\begin{array}{l}\text { (1) } 65 \\
\text { (2) } 170\end{array}$ \\
\hline & 2.4 & $\begin{array}{l}\text { (1) } 115 \\
\text { (2) } 300\end{array}$ & $\begin{array}{l}\text { (1) } 90 \\
\text { (2) } 225\end{array}$ & $\begin{array}{l}\text { (1) } 120 \\
\text { (2) } 250\end{array}$ \\
\hline \multirow{2}{*}{$\mathrm{N}_{+}$} & 1 & $\begin{array}{l}\text { (1) } 75 \\
\text { (2) } 200\end{array}$ & $\begin{array}{l}\text { (1) } 60 \\
\text { (2) } 150\end{array}$ & $\begin{array}{l}\text { (1) } 70 \\
\text { (2) } 175\end{array}$ \\
\hline & 2.4 & $\begin{array}{l}\text { (1) } 145 \\
\text { (2) } 350\end{array}$ & $\begin{array}{l}\text { (1) } 110 \\
\text { (2) } 275\end{array}$ & $\begin{array}{l}\text { (1) } 133 \\
\text { (2) } 280\end{array}$ \\
\hline
\end{tabular}

The distribution of the ions generates a matrix in profile of implanted ions. It is assumed that $\mathrm{N}+$ ions can reach slightly deeper regions than $\mathrm{F}+$ when stimulated with the same energy for implantation. Increasing the energy from 1 to $2.4 \mathrm{keV}$, the ions can reach deeper distances in the targets. Figure 2 shows, respectively, the histogram of ions penetrating on to rigid PVC surface (a) F+ ions (b) N+ ions; as function of target depth, while Fig. 3 shows, respectively, the histogram of (a) F+ ions (b) N+ ions penetrating on to PET mylar surface.

These fluency values $\left(12 \times 10^{5}\right.$ to $18 \times 10^{5}$ atoms/area $)$ are fairly low, and they are not reported in preview studies, which represent new conditions of simulation. It was concluded that, at the same irradiation condition, PET presented lower penetration than PVC for both $\left(\mathrm{F}^{+}\right)$and $\left(\mathrm{N}^{+}\right)$ions projectile. Figure 4 shows, respectively, the histogram of ions penetrating on to LDPE surface (a) $\mathrm{F}^{+}$ions $(\mathrm{b}) \mathrm{N}^{+}$ions; as function of target depth. 
(a)

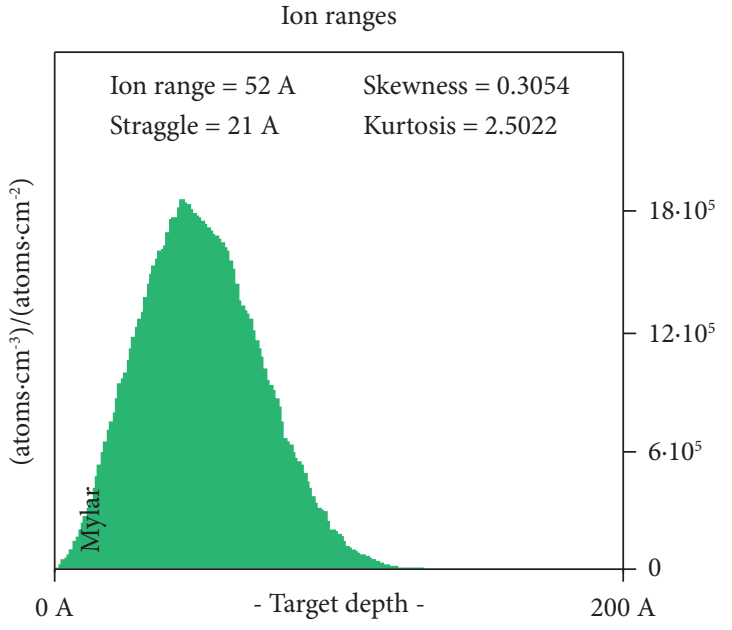

(b)

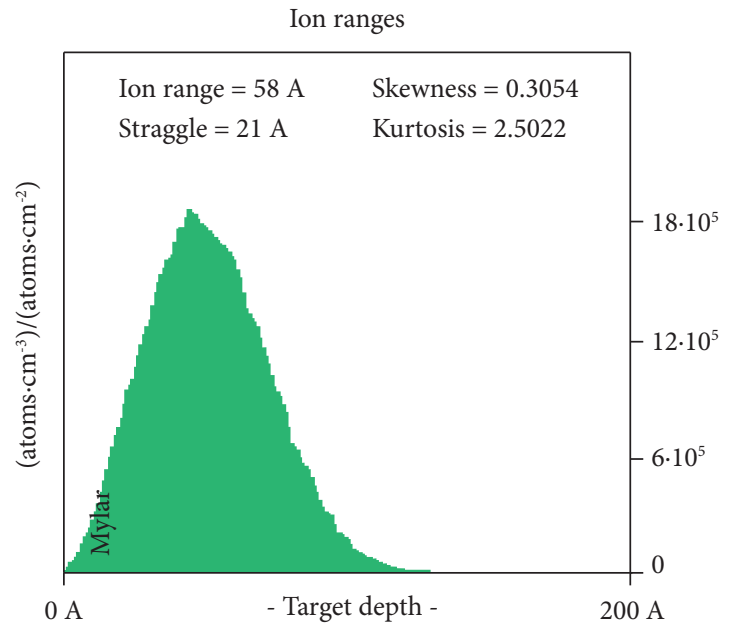

Figure 2: (a) Depth $(\AA ̊)$ of incident ions $\left(\mathrm{F}^{+}\right)$for PVC using incident energy of $1 \mathrm{keV}$; (b) depth $(\AA)$ of incident ions $\left(\mathrm{N}^{+}\right)$ for PVC using incident energy of $1 \mathrm{keV}$. The histogram shows mean and maximum value ranges.

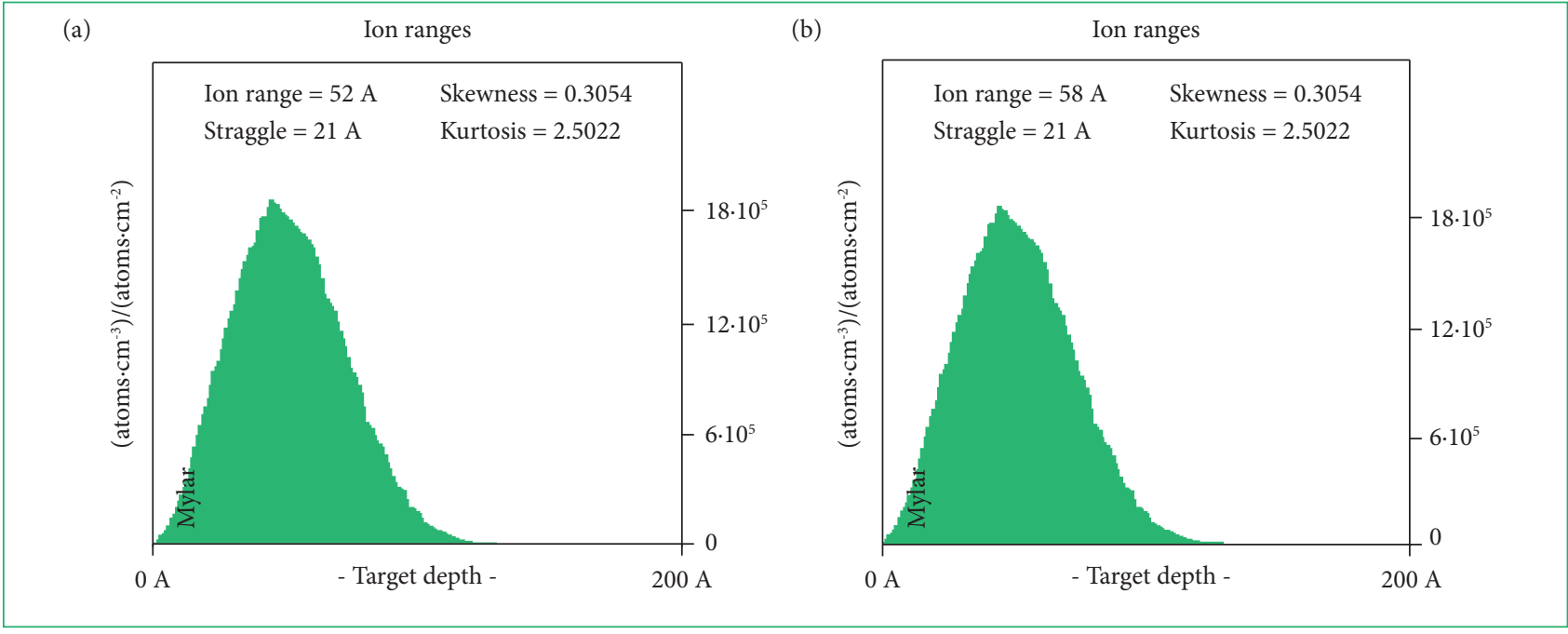

Figure 3: (a) Depth $(\AA ̊)$ of incident ions $\left(\mathrm{F}^{+}\right)$for PET using incident energy of $1 \mathrm{keV}$; (b) depth $(\AA)$ of incident ions $\left(\mathrm{N}^{+}\right)$ for PET using incident energy of $1 \mathrm{keV}$. The histogram shows mean and maximum value ranges.

(a)

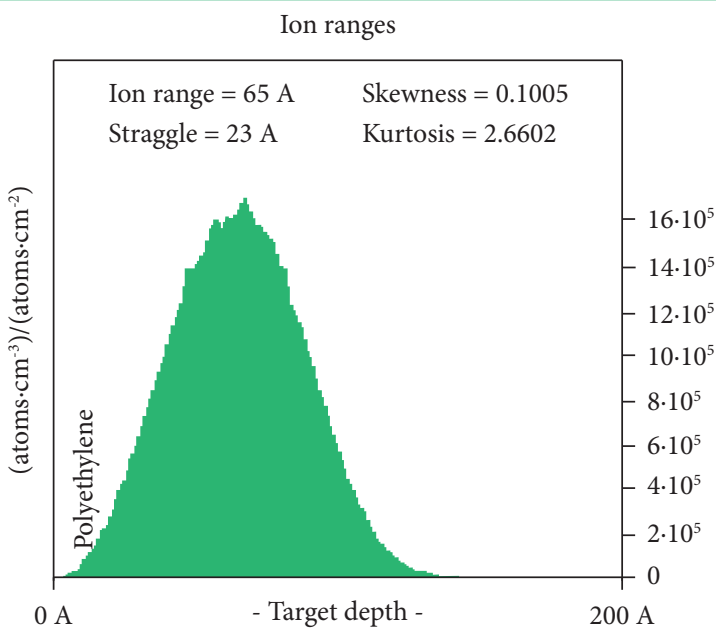

(b)

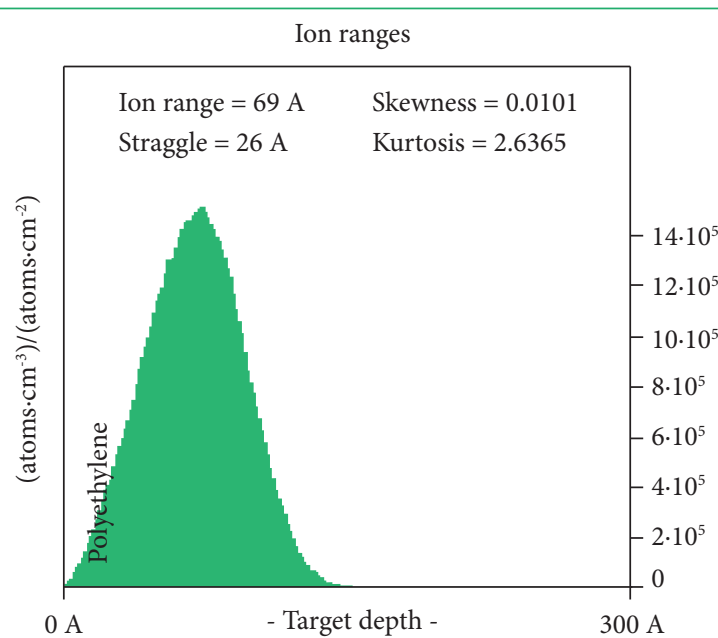

Figure 4: (a) Depth $(\AA)$ of incident $(F+)$ ions, using incident energy of $1 \mathrm{keV}(\mathrm{b})$ Depth $(\AA)$ of incident ions $(\mathrm{N}+)$, using incident energy of $1 \mathrm{keV}$, both for LDPE. The histogram shows mean and maximum value ranges. 
Polyethylene, in turn, has a less dense, less branched structure. It is expected that the same input energies promote greater depths of penetration of $\left(\mathrm{F}^{+}\right)$and $\left(\mathrm{N}^{+}\right)$ions projectile. In most cases, the values are higher than in PET, and lower than in PVC. Straggling is the mean roots of variance, presented in $\sim 0.15 \%$ of the total range of penetrating ions (<30 $\AA$; nonextreme). Considering the three polymers as low-density materials, those straggling values are relatively larger. Skewness presented (dimensionless) positive and small values indicating that all the peaks are a bit away from the surface, and the most probable depth is a bit smaller than the mean ${ }^{30}$. Kurtosis (dimensionless) means how tall and sharp the peak is, and, for all curves, it presented values between 0 and 3, indicating a leptokurtic (abbreviated tails) $)^{31}$.

\section{Energy loss (ions and recoils)}

As result of ion bombardment, the SRIM software recognizes the energy loss - $d E / d x$ in (\%), which summaries the loss energy from the ion to the target electrons, and being possible to estimate the ionization, vacancy and phonons contribution (\%) for either ions or recoil atoms (eV/Å). The same target polymeric materials were used. Table 3 shows the results about energy loss (eV/Å-ion) for $\mathrm{F}^{+}$and $\mathrm{N}^{+}$ions and recoils.

Table 3: Ion loss energy $(-\mathrm{dE} / \mathrm{dx})$ of incident fluorine ions $\left(\mathrm{F}^{+}\right)$, and nitrogen $\left(\mathrm{N}^{+}\right)$, using the incident energy of 1 keV. Three parameters of loss energy are presented for the three polymer targets investigated: (i) ionization, (ii) vacancy, (iii) phonons.

\begin{tabular}{|c|c|c|c|c|c|}
\hline $\begin{array}{l}\text { Ion incident } \\
(99,999)\end{array}$ & Type & $\begin{array}{c}\text {-dE/dx (energy loss) } \\
\text { [eV/Å-ion] }\end{array}$ & PVC & PET & LDPE \\
\hline \multirow{2}{*}{$\begin{array}{c}\mathrm{F}+ \\
(1 \mathrm{keV})\end{array}$} & ions & $\begin{array}{l}\text { Ionization } \\
\text { Vacancy } \\
\text { Phonons }\end{array}$ & $\begin{array}{c}7.75 \\
2.28 \\
12.35\end{array}$ & $\begin{array}{c}8.75 \\
1.94 \\
11.94\end{array}$ & $\begin{array}{c}9.68 \\
2.6 \\
13.5\end{array}$ \\
\hline & recoils & $\begin{array}{l}\text { Ionization } \\
\text { Vacancy } \\
\text { Phonons }\end{array}$ & $\begin{array}{c}14.85 \\
1.37 \\
61.37\end{array}$ & $\begin{array}{c}15.61 \\
1.21 \\
60.55\end{array}$ & $\begin{array}{c}17.4 \\
1.2 \\
55.6\end{array}$ \\
\hline \multirow{2}{*}{$\stackrel{\mathrm{N}+}{(1 \mathrm{keV})}$} & ions & $\begin{array}{l}\text { Ionization } \\
\text { Vacancy } \\
\text { Phonons }\end{array}$ & $\begin{array}{c}11.78 \\
2.25 \\
12.14\end{array}$ & $\begin{array}{c}13.9 \\
1.88 \\
11.48\end{array}$ & $\begin{array}{c}14.6 \\
2.52 \\
12.48\end{array}$ \\
\hline & recoils & $\begin{array}{l}\text { Ionization } \\
\text { Vacancy } \\
\text { Phonons }\end{array}$ & $\begin{array}{c}14.00 \\
1.38 \\
58.45\end{array}$ & $\begin{array}{c}14.76 \\
1.21 \\
57.48\end{array}$ & $\begin{array}{c}16.88 \\
1.32 \\
52.95\end{array}$ \\
\hline
\end{tabular}

It concluded that the most $-\mathrm{dE} / \mathrm{dx}$ (\%) of energy loss is associated to the phonons generation in higher proportions, following the ionization process, and, lastly, in lower proportions, the vacancy for ions and recoils. Table 4 shows the results of binding and displacement energies; the number of backscattered ions, $\mathrm{n}_{\mathrm{B}}$ and vacancies produced per ion $\mathrm{n}_{\mathrm{V}}$.

Table 4: Ion loss energy $(-\mathrm{dE} / \mathrm{dx})$ of incident $\left(\mathrm{F}^{+}\right)$, and $\left(\mathrm{N}^{+}\right)$ions, using the incident energy of $1 \mathrm{keV}$. Three parameters of loss energy are presented:

(i) lattice binding energy (LBE); (ii) surface binding energy (SBE); (iii) displacement energy (DE). In addition, (iv) the number of backscattered ions and $(v)$ the number of vacancy/ion (incident) were calculated for the three polymer targets.

\begin{tabular}{|c|c|c|c|c|}
\hline $\begin{array}{l}\text { Ion incident } \\
(99,999)\end{array}$ & $-\mathrm{dE} / \mathrm{dx}$ (energy loss) & PVC & PET & LDPE \\
\hline \multirow{5}{*}{$\begin{array}{c}\mathrm{F}+ \\
(1 \mathrm{keV})\end{array}$} & LBE (eV/Å) (associated to phonons yield) & 3 & 3 & 3 \\
\hline & SBE (eV/Å) (associated to sputtering yield) & $\begin{array}{l}2 \mathrm{H}-7.4 \mathrm{C}-2 \mathrm{Cl} \\
\text { Mean values } \pm 0\end{array}$ & $\begin{array}{c}2 \mathrm{H}-7.41 \mathrm{C}-2 \mathrm{O} \\
\text { Mean values } \pm 0\end{array}$ & $\begin{array}{c}2 \mathrm{H}-7.41 \mathrm{C} \\
\text { Mean value } \pm 0\end{array}$ \\
\hline & $\mathrm{DE}(\mathrm{eV} / \AA \AA$ ) (associated to energy to recoils) & $\begin{array}{c}10 \mathrm{H}-28 \mathrm{C}-25 \mathrm{Cl} \\
\text { Mean values } \pm 0\end{array}$ & $\begin{array}{c}10 \mathrm{H}-28 \mathrm{C}-28 \mathrm{O} \\
\text { Mean values } \pm 0\end{array}$ & $\begin{array}{c}10 \mathrm{H}-28 \mathrm{C} \\
\text { Mean values } \pm 0\end{array}$ \\
\hline & Number of backscattered ions (NB) & 1709 & 59 & 11 \\
\hline & Number of vacancy /ion (Nv) & 13.9 & 11.9 & 14.8 \\
\hline \multirow{5}{*}{$\begin{array}{c}\mathrm{N}+ \\
(1 \mathrm{keV})\end{array}$} & LBE (eV/Å) (associated to phonons yield) & 3 & 3 & 3 \\
\hline & SBE (eV/Å) (associated to sputtering yield) & $\begin{array}{c}2 \mathrm{H}-7.41 \mathrm{C}-2 \mathrm{Cl} \\
\text { Mean values } \pm 0\end{array}$ & $\begin{array}{c}2 \mathrm{H}-7.41 \mathrm{C}-2 \mathrm{O} \\
\text { Mean values } \pm 0\end{array}$ & $\begin{array}{c}2 \mathrm{H}-7.41 \mathrm{C} \\
\text { Mean values } \pm 0\end{array}$ \\
\hline & $\mathrm{DE}(\mathrm{eV} / \AA \AA$ ) (associated to energy to recoils) & $\begin{array}{c}10 \mathrm{H}-28 \mathrm{C}-25 \mathrm{Cl} \\
\text { Mean values } \pm 0\end{array}$ & $\begin{array}{c}10 \mathrm{H}-28 \mathrm{C}-28 \mathrm{O} \\
\text { Mean values } \pm 0\end{array}$ & $\begin{array}{c}10 \mathrm{H}-28 \mathrm{C} \\
\text { Mean values } \pm 0\end{array}$ \\
\hline & Number of backscattered ions (NB) & 2363 & 292 & 52 \\
\hline & Number of vacancy /ion (Nv) & 13.7 & 11.6 & 14.6 \\
\hline
\end{tabular}


Lattice binding energy $(\mathrm{LBE})$ is the energy that every recoiling target atoms $(\mathrm{C}, \mathrm{H}, \mathrm{Cl}, \mathrm{O})$ lose when they leave their lattice site and recoil in the target, going into phonons. Surface binding energy (SBE) is the energy that target atoms must overcome to leave the surface of the target, including all surface nonlinearity's produced by radiation damage, which is different from the binding chemical energy, EB $(2.9<\mathrm{EB}<8.0)$ for the three polymers according to Sant'Ana16. The only value found as comparative data is related to SBE of the pure carbon $(7.37 \mathrm{eV})$, according to Nichols et al.32, which is next to the value calculated by the SRIM $2008(7.41 \mathrm{eV})$. Displacement energy (DE) is the energy that a recoil atom needs to overcome the target's lattice forces and to move more than, one atomic spacing away from its original site. The number of random backscattered ions for $\mathrm{N}+$ is relatively higher than for $\mathrm{F}+$, because $\mathrm{N}+$ is a lighter ion than $\mathrm{F}+$.

\section{DISCUSSION}

\section{Surface properties (laboratory samples characterization)}

After $\mathrm{F}^{+}$implantation over the polymers during plasma phase, $\mathrm{C}-\mathrm{F}$ bonds in great proportion is formed at surface, as indicated by XPS analysis in Sant'Ana's work ${ }^{16}$, becoming similar to Teflon (considerable hydrophobic material). According to literature, the exposure of the polymer surface in fluorine is capable of replacing hydrogen atoms with fluorine atoms, increasing $\mathrm{C}-\mathrm{F}$ bonds into the backbone, which possess nonattraction to pure water; thus, increasing the hydrophobic character.

Surface wettability dependent on surface chemical structure ${ }^{33}$ and is commonly characterized by contact angle ${ }^{34,35}$. Besides the increase of $\Theta$ being stable within 30 days monitored, the roughness ( $\mathrm{Rz}$ ) of the polymers had a wispy increase (from 4.38 to $12.6 \mathrm{~nm}$ for PVC, and from 1.8 to $2.6 \mathrm{~nm}$ for PET) after PIII. This process enhances the interface roughness as the interface moves through the amorphous phase. The optical transmittance T $(\lambda)$ for PET indicated a wispy increase, $2 \%$, reaching $84 \%$. The structure of the polymers is suggested as being a-C:H:F (no hydrogen was detected by XPS). For instance, under the implantation over LDPE using fluorine ions, the carbon concentrations in the implanted layer comes to saturation at level of 40 at.\%. After $\mathrm{N}^{+}$implantation, new functions groups of (-CN-) and (-CON-), even in low proportion, and groups containing $\mathrm{O}$ such as $(\mathrm{C}-\mathrm{O}),(\mathrm{C}=\mathrm{O}),(\mathrm{C}=\mathrm{C}),(-\mathrm{OH})$ in higher proportions can appear and to be localized in until $35 \mathrm{~nm}$ of depth for PVC and PET. Results in the introduction of polar groups from the surrounding environment onto the surface increase its wettability ${ }^{36,37}$. About 33\% of O proportion was observed on the surface of PVC. In previews works, the exposure of the polymer surface to nitrogen plasmas caused the surface with intermediate wettability to become hydrophilic, because of its chemical affinity with O containing groups and others polar groups were confirmed by XPS and FTIR, including unsaturation bonds.

The structure of the polymers after the implantation was suggested to be a-C:H:O "doped" with N (at.\% less than $3 \%$ ); no hydrogen was detected by XPS. In addition, Fourier transform infrared spectroscopy by attenuated total reflectance (ATR-FTIR) proved the considerable presence of $\mathrm{O}$ and $\mathrm{O}$-containing groups as result of the $\mathrm{N}^{+}$ion implantation. This fact comprises the decrease of $\Theta$, reaching $\sim 14^{\circ}$ for PVC, $\sim 19^{\circ}$ for PET and $\sim 9^{\circ}$ for LDPE. The literature suggests the decrease of optical gap in PET after $\mathrm{N}^{+}$ion implantation. Nathawat et al. ${ }^{38}$ have observed that there is a significant decrease in the value of energy gap from $3.9 \mathrm{eV}$ (virgin PET) to $1.6 \mathrm{eV}$ in the PET specimens with $\mathrm{N}^{+}$ions implantation. Shekhawat et al. ${ }^{39}$ and Popok et al. ${ }^{40}$ have also studied the effect of $\mathrm{N}^{+}$ion implantation on the optical properties of different polymers. Ahmed et al. ${ }^{41}$ observed high absorption of UV-spectra between 190 and $300 \mathrm{~nm}$, which comprises the decrease of optical transmittance in theses ranges.

In this study, $\mathrm{T}(\lambda)$ was reduced in until $10 \%$ for LDPE after $\mathrm{N}^{+}$ion implantation, mainly in these ranges. On the other hand, $\mathrm{T}(\lambda)$ sparsely increased for PET. All these studies point towards the structural rearrangement in the polymeric matrices as a result of ion implantation. It has been associated with chain scission and cross-linking of free radicals, as it is a well-known fact that nuclear energy losses are largely responsible for chain scission, whereas electronic energy losses are for cross-linking ${ }^{18}$. When an energetic ion impinges on a polymer, its orbital electrons are stripped off and the nucleus becomes almost naked until the ion velocity slows down below the Bohr electron velocity of the medium ${ }^{42}$. Besides scission and cross-link, common gases produced upon ion irradiation include $\mathrm{H}_{2}, \mathrm{CH}_{4}, \mathrm{CO}, \mathrm{CO}_{2}, \mathrm{HCl}, \mathrm{H}_{2} \mathrm{O}, \mathrm{C}_{2} \mathrm{H}_{2}, \mathrm{CF}_{3}, \mathrm{C}_{2} \mathrm{~F}_{4}$, etc. ${ }^{43,44}$.

The literature reports the loss of optical transmittance at visible light $\mathrm{T}(\lambda)$ as a consequence of adjacent carbon chains (crosslinks), acting as a barrier for the free path of radiation through the polymeric lattice $e^{45,47}$, which in fact approximates adjacent chains, causes entanglements, and, then, may fill voids contained in the structure of the polymer chains. On the other hand, these mechanisms are responsible to the barrier properties improvement, which were confirmed analyzing the decrease of water vapor transmission rate (from $6.12 \mathrm{~g} / \mathrm{m}^{2}$ day to $1.05 \pm 0.17 \mathrm{~g} / \mathrm{m}^{2}$ day for PET and from $6.4 \mathrm{~g} / \mathrm{m}^{2}$ day to $2.45 \mathrm{~g} / \mathrm{m}^{2} \mathrm{day}$ for LDPE). These values are regarded to a high gas barrier material. Similar results are reported by Czeremuszkin et al., Garcia-Ayuso et al. and Henry et al. ${ }^{48-50}$. In other studies, plasma treatment was useful to improve water vapor barrier on PET and other packaging systems ${ }^{51,52}$. It was concluded that a physical structure on the polymer surface changed, attending ions housing from tens to 
hundreds of depth, and that seems to be one of reasons for changes in wettability, optical transmittance at visible light and enhancement of gas barrier properties in PET bottles and LDPE films ${ }^{53}$, as confirmed by Sant'Ana ${ }^{16}$.

\section{SRIM simulation}

In the first signs, the literature report that energetic ions interact with matter by losing their energy in the matter predominantly by two different mechanisms: the nuclear energy loss (Sn) and the electronic energy loss (Se). Nuclear energy loss arises from "momentum-transfer" between the energetic ion and the target nuclei, which causes atomic displacements and phonons ${ }^{18}$.

Experimental results suggest that insaturation can occurs when ion pairs in two neighboring chains overlap ${ }^{54}$, because the SRIM simulation does not take into account the compositional and structural changes of the polymer substrate in the course of the implantation. The incident ion primarily undergoes $\mathrm{Sn}$ at low energies $(\sim 1 \mathrm{keV} / \text { nucleon })^{55}$. In this study, the major energy loss was observed for phonons generation, which comprises to the "nuclear energy loss"

Nuclear stopping involves the transfer of momentum from the ion to a host matrix atom, or recoil atom. If the momentum transfer is small, the energy imparted to the recoil atom will be dissipated by phonons. As the process of irradiation is, then, continuous, ion beam causes electronic excitation or removes valence electrons (ionization) via electronic energy loss, "free radicals" may be generated in the polymer chains ${ }^{56}$.

Electronic stopping occurs by two processes, both involving electromagnetic interaction between the positively charged ion and target electrons. Electronic energy loss can be explained by the mechanism called glancing collision (inelastic scattering, with small momentum transfer $)^{18}$. In thesis, $\mathrm{F}^{+}$and $\mathrm{N}^{+}$ions are considered as "light ions" $(\mathrm{amu}<20)$ When they are entering into polymer targets, they immediately interact with many electrons simultaneously. In such encounter, the electrons experience and impulse from the attractive coulomb forces as the projectile ions pass their areas.

The simulation shows that, for ion beam energy between 1 to $2.4 \mathrm{keV}$, these impulses are sufficient to produce ionization, then the velocity (kinetic energy) of the ion will decrease until it is stopped from tenths to few hundreds ångström of depth in polymers. In this process, bonds of hydrogen are easily broken due to its weak bonds ${ }^{57}$. In fact, high voltage influences on the surface bonding configuration ${ }^{58}$.

In this study, the considerable energy loss for ionization was observed (fractions between 10 and $20 \%$ of energy), that comprises the mechanism of "electronic energy loss", but in minor \% than for phonons generation, in which the nuclear energy loss is predominant than electronic energy loss. The distribution of energy loss in \% was similar to the all polymer targets. In addition, a small fraction of vacancy was produced as result of ion bombardment $(<4 \%)$. Moreover, since the ion energy $(1 \mathrm{keV})$ is much higher than the binding energy of atoms in a polymer, the ion imparts enough energy to the primary replaced atom (recoil) for the following replacements, thus producing nonlinear collision cascades ${ }^{18,59}$. Displaced recoils are capable of creating further recoils and ionization. Then, the loss of energy in $\mathrm{eV} / \AA$ was associated for either ions or recoils, being more predominant for recoils than ions (for ionization and phonons). For vacancy, the energy loss was predominant for ions than recoils, which were similar to the three polymer targets. The energy losses were estimated by applying a modified KinchinPease model of recoils ${ }^{60}$. Although both electronic and nuclear processes cause crosslinking as well as scissions, it has been found that the most important parameter to achieve a high degree of crosslinking is electronic, whilst nuclear, tends to cause degradation ${ }^{61}$ and unsaturation, and subsequent chemical reactions results in the creation of excessive double bonds ${ }^{62}$ and oxidized structures ${ }^{63}$.

This fact comprises the XPS and FTIR analyses that presented a number of O-containing groups in the PIII processes, mainly for nitrogen plasma treatment. For a given energy, smaller atoms penetrate deeper; the process can originate fewer nuclear displacements than heavier ones. It comprises the ion distribution and range simulation, whereas the $\mathrm{N}^{+}$ions reached more depth distances, as reported in this study. However, their maximum attainable electronic is smaller because they have fewer nucleons and attain a lower charge state when stripped ${ }^{16}$.

It is worth mentioning that the ions projectile reaches more depth distances in PVC and LDPE than in the PET. Probably, the presence of the aromatic ring on PET does confer greater resistance against ionic bombardments, confirming the lower penetration values for PET in relation to PVC. The number of random backscattered ions for $\mathrm{N}^{+}$is relatively higher than for $\mathrm{F}^{+}$, because $\mathrm{N}^{+}$is a lighter ion than $\mathrm{F}^{+}$. Lighter ions tend to backscatter toward the substrate surface, while heavy ions tend to forward-scatter into the bulk. In all cases, they presented nonextreme values.

Diffusion is a vacancy mechanism and tends to be higher in damage regions; however, the SRIM does not recognizes any parameter to explain the vacancy mechanism besides the "collision events" and, also, there is no parameter related to the heating during the process of ion implantation. In practice, the samples were implanted in room temperature (298 K). However, the collision events presented more vacancies produced in shallow regions than in deeper regions by an unsymmetrical Gaussian. According to literature, diffusion depends on the size, shape, and polarity of the penetrating molecule, degree of cross-linking 
and polymer chain segmental motion of the polymer matrix ${ }^{64}$. The chemical elements permeation into semicrystalline polymers is confined into the amorphous regions.

The number of vacancies were quite similar between the three targets for $\mathrm{F}^{+}$and $\mathrm{N}^{+}$, because PVC, PET and LDPE presented similar chemical structure and chains, presenting double bonds and unsaturation. Comparing $\mathrm{F}^{+}$and $\mathrm{N}^{+}$ions, the authors of this work consider that they have near sizes, shapes and polarity. Anyway, the interstitial atoms occur during the irradiation process $^{65}$, acting to suppress diffusion of such "impurities" (incident ions). More details of the plasma treatment using nitrogen and fluorine on this polymer and the physical simulation using SRIM can be found in other sources ${ }^{66-70}$.

\section{CONCLUSION}

The use of computational tools such as SRIM/TRIM calculations in conjunction with Monte Carlo code were useful to compare experimental and simulated data attending to the ion implantation process. Analogously, for $1 \mathrm{keV}$ (equivalent to $1000 \mathrm{~V}$ high-voltage negative pulses) of input energy results in depths from $\left.45 \AA \mathrm{F}^{+}\right)$to $79 \AA\left(\mathrm{N}^{+}\right)$of modified layer. These values can be associated to the "loss of energy $(-\mathrm{dE} / \mathrm{dx})$ " during ions penetration in the targets leading to a random scattering. In practice, $\mathrm{SF}_{5}{ }^{+}$are common radicals in $\mathrm{SF}_{6}$ plasma; however, they are broken due to the impact with surface target atoms.

The outcome is that those values of modified layer are enough to bring up collision events related to the vacancies produced and energy to recoils related to Kinchin-Pease damage calculation, which reflects in surface properties alterations: wetting, transmittance at visible light and gas barrier properties. All of them are interesting in the polymer science and nanotechnology.

\section{FUNDING}

Conselho Nacional de Desenvolvimento Científico e Tecnológico [https://doi.org/10.13039/501100003593]

Fundação de Amparo à Pesquisa do Estado de São Paulo [https://doi.org/10.13039/501100001807]

\#Process 2017/15853-0

Coordenação de Aperfeiçoamento de Pessoal de Nível Superior [https://doi.org/10.13039/501100002322]

\section{REFERENCES}

1. Gaylord NG, Adler G. Radiation chemistry of polymeric systems high polymers, A. Chapiro, Ed., Interscience, New York, 1962 , xvi + 712 pp. \$21.00. J Polym Sci A1. 1963;1(6):2237. https://doi.org/10.1002/pol.1963.100010646

2. Dole M. The radiation chemistry of macromolecules. New York: Academic Press; 1972. https://doi.org/10.1016/C2013-0-10595-8

3. Kondyurin A, Bilek MMM. Ion beam treatment of polymers: application aspects from medicine to space. Amsterdam: Elsevier; 2014.

4. Anderson KS, Schreck KM, Hillmyer MA. Toughening polylactide. Polym Rev. 2008;48(1):85-108. https://doi. org/10.1080/15583720701834216

5. Arefi F, Andre V, Montazer-Rahmati P, Amouroux J. Plasma polymerization and surface treatment of polymers. Pure Appl Chem. 1992;64(5):715-23. https://doi.org/10.1351/pac199264050715

6. D'Agostino R, Favia P, Fracassi F. Plasma processing of polymers. Netherlands: Springer; 1997.

7. Ensinger W. Plasma immersion ion implantation for metallurgical and semiconductor research and development. Nucl Instrum Meth B. 1996;120(1-4):270-81. https://doi.org/10.1016/S0168-583X(96)00526-5

8. Brown IG, Anders A, Anders S, Dickinson MR, MacGill RA. Metal ion implantation: conventional versus immersion. J Vac Sci Technol B. 1994;12:823. https://doi.org/10.1116/1.587353

9. Brutscher J, Günzel R, Möller W. Plasma immersion ion implantation using pulsed plasma with d.c. and pulsed high voltages. Surf Coat Tech. 1997;93(2-3):197-202. https://doi.org/10.1016/S0257-8972(97)00044-310

10. Goorsky M. Ion Implantation. Croatia: Tech Publisher; 2012. https://doi.org/10.5772/1881

11. Fink D. Fundamentals of ion-irradiated polymers. Berlin: Springer-Verlag; 2004. https://doi.org/10.1007/978-3-662-07326-1

12. Vukušić T, Vesel A, Holc M, Ščetar M, Jambrak AR, Mozetič M. Modification of physico-chemical properties of acryl-coated polypropylene foils for food packaging by reactive particles from oxygen plasma. Materials. 2018;11(3):372. https://doi.org/10.3390/ ma11030372 
13. Vacík J, Hnatowicz V, Červená J, Peřina V, Popok V, Odzhaev V, et al. High fluence boron implantation into polyimide. Nucl Instrum Meth B. 1999;148(1-4):1126-30. https://doi.org/10.1016/S0168-583X(98)00814-314

14. Shekhawat N, Aggarwal S, Sharma A, Nair KGM. N+ implantation-induced surface hardening of poly (allyl diglycol carbonate) polymer. J Macromol Sci B. 2016;55(7):652-61. https://doi.org/10.1080/00222348.2016.1187046

15. Šiljegović M, Kačarević-Popović ZM, Krklješ AN, Stojanović Z, Jovanović ZM. Effect of N4+ and C4+ ion beam bombardment on the optical and structural characteristics of ethylene-norbornene copolymer (TOPAS). Nucl Instrum Meth B. 2011;269(7):708-15. https:// doi.org/10.1016/j.nimb.2011.01.134

16. Sant'Ana PL. Plásticos comerciais tratados a plasma para dispositivos ópticos e embalagens alimentícias [thesis]. [Sorocaba]: Universidade Estadual Paulista Júlio de Mesquita Filho, Faculdade de Ciências; 2014. [cited Apr 1 2020]. Available at: https:// repositorio.unesp.br/handle/11449/110893

17. Dong H, Bell T. State-of-the-art overview: ion beam surface modification of polymers towards improving tribological properties. Surf Coat Tech. 1999;111(1):29-40. https://doi.org/10.1016/S0257-8972(98)00698-718

18. Lee EH. Ion-beam modification of polymeric materials - fundamental principles and applications. Nucl Instrum Meth B. 1999;151(14):29-41. https://doi.org/10.1016/S0168-583X(99)00129-9

19. Kondyurin A, Bilek MMM. Ion beam treatment of polymers: application aspects from medicine to space. Amsterdam: Elsevier; 2008 . https://doi.org/10.1016/B978-0-08-044692-9.X5001-8

20. Popok VN, Khaibullin RI, Tóth A, Beshliu V, Hnatowicz V, Mackova A. Compositional alteration of polyimide under high fluence implantation by Co+ and Fe+ ions. Surf Sci. 2003;532-535:1034-9. https://doi.org/10.1016/S0039-6028(03)00408-4

21. Cowie JM. Polymers: chemistry and physics of modern materials. Great Britain: Intertext; 2007;3,520 p.

22. Lee EH, Rao GR, Mansur LK. Super-hard-surfaced polymers by high-energy ion-beam irradiation. Trends Polymer Sci. 1996;4(7):229-37.

23. Ziegler JF, Biersack JP. The Stopping and Range of Ions in Matter. In: Bromley DA. (eds) Treatise on Heavy-lon Science. Springer: Boston; 1985. https://doi.org/10.1007/978-1-4615-8103-1_3

24. Rautray TR, Narayanan R, Kim K-H. Ion implantation of titanium based biomaterials. Prog Mater Sci. 2011;56(8):1137-77. https://doi. org/10.1016/j.pmatsci.2011.03.002

25. Kavetskyy TS, Stepanov AL. Spectroscopic investigations of ion-induced processes in polymethylmethacrylate at low-energy boronion implantation. In: XXII International Conference on Ion-Surface Interactions (ISI-2015). Moscow: NRNU MEPh I; 2015.

26. Okuji S, Sekiya M, Nakabayashi M, Endo H, Sakudo N, Nagai K. Surface modification of polymeric substrates by plasma-based ion implantation. Nucl Instrum Meth B. 2006;242(1-2):353-6. https://doi.org/10.1016/j.nimb.2005.08.153

27. Norgett, M.J. and Torrens, M.T. A proposed method of calculating displacement dose rates. Nucl. Eng. Des. 1974;33(1):50-54. https://doi.org/10.1016/0029-5493(75)90035-7

28. Kinchin GH, Pease RS. The displacement of atoms in solids by radiation. Rep Prog Phys. 1955;18:1-51. https://doi.org/10.1088/0034$4885 / 18 / 1 / 301$

29. Ziegler JF, Manoyan JM. The stopping of ions in compounds. Nucl Instrum Meth B. 1988;35(3-4):215-28. https://doi.org/10.1016/0168$583 \times(88) 90273-X$

30. Sheskin DJ. Handbook of parametric and nonparametric statistical procedures. Boca Raton: Chapman and Hall/CRC; 2011.

31. Westfall PH. Kurtosis as peakedness, 1905-2014. R.I.P. Am Stat. 2014;68(3):191-5. https://doi.org/10.1080/00031305.2014.917055

32. Nichols JH, Jaworski MA, Schmid K. Sensitivity of WallDYN material migration modeling to uncertainties in mixed-material surface binding energies. Nucl Mater Energy. 2017;12:513-7. https://doi.org/10.1016/j.nme.2017.01.011

33. Kotál V, Švorčík V, Slepička P, Sajdl P, Bláhová O, Šutta P, et al. Gold coating of poly(ethylene terephthalate) modified by argon plasma. Plasma Process Polym. 2007;4(1):69-76. https://doi.org/10.1002/ppap.200600069

34. Yuan Y, Lee TR. Contact angle and wetting properties. In: Bracco G, Holst B (Eds.). Surface science techniques. Berlin: Springer; 2013. https://doi.org/10.1007/978-3-642-34243-1_1

35. Ročková-Hlaváčková K, Švorčík V, Bačáková L, Dvořánková B, Heitz J, Hnatowicz V. Bio-compatibility of ion beam-modified and RGDgrafted polyethylene. Nucl Instrum Meth B. 2004;225(3):275-82. https://doi.org/10.1016/j.nimb.2004.05.004

36. Kondyurin A, Gan BK, Bilek MMM, Mizuno K, McKenzie DR. Etching and structural changes of polystyrene films during plasma immersion ion implantation from argon plasma. Nucl Instrum Meth B. 2006;251(2):413-8. https://doi.org/10.1016/j.nimb.2006.06.027

37. Rangel EC, Santos NM, Bortoleto JRR, Durrant SF, Schreiner WH, Honda RY, et al. Treatment of PVC using an alternative Iow energy ion bombardment procedure. Appl Surf Sci. 2011;258(5):1854-61. https://doi.org/10.1016/j.apsusc.2011.10.061

38. Nathawat R, Kumar A, Kulshrestha V, Vijay YK, Kobayashi T, Kanjilal D. Study of surface activation of PET by low energy (keV) Ni+ and $\mathrm{N}+$ ion implantation. Nucl Instrum Meth B. 2008;266(21):4749-56. https://doi.org/10.1016/j.nimb.2008.07.026

39. Shekhawat N, Aggarwal S, Sharma A, Nair KGM. Surface hardening in N+ implanted polycarbonate. J Mater Sci. 2015;50:3005-13. https://doi.org/10.1007/s10853-015-8817-3 
40. Popok VN, Odzhaev VB, Kozlov IP, Azarko II, Karpovich IA, Sviridov DV. Ion beam effects in polymer films: Structure evolution of the implanted layer. Nucl Instrum Meth B. 1997;129(1):60-4. https://doi.org/10.1016/S0168-583X(97)00208-5

41. Ahmed SF, Moon M-W, Kim C, Jang Y-J, Han S, Choi J-Y, et al. Optical properties of surface modified polypropylene by plasma immersion ion implantation technique. Appl Phys Lett. 2010;97(8):081908. https://doi.org/10.1063/1.3481417

42. Adamson AW. Physical chemistry of surfaces. New York: Wiley-Interscience; 1977.

43. Chapiro A. Chemical modifications in irradiated polymers. Nucl Instrum Meth B. 1988;32(1-4):111-4. https://doi.org/10.1016/0168$583 \times(88) 90191-7$

44. Lewis MB, Lee EH. Residual gas and ion-beam analysis of ion-irradiated polymers. Nucl Instrum Meth B. 1991;61(4):457-65. https:// doi.org/10.1016/0168-583X(91)95323-6

45. Nassau K. The fifteen causes of color:The Physics and chemistry of color. New York: John Wiley \& Sons; 1983:12(1):4-26. https:// doi.org/10.1002/col.5080120105

46. Factor A, Carnahan JC, Dorn SB, Van Dort PC. The chemistry of $\bigotimes$-irradiated bisphenol-A polycarbonate. Polym Degrad Stabil. 1994;45(1):127-37. https://doi.org/10.1016/0141-3910(94)90188-0

47. Wallace JS, Sinclair MB, Gillen KT, Clough RL. Color center annealing in $\otimes$ - irradiated polystyrene, under vacuum and air atmospheres Radiat Phys Chem. 1993;41(1-2):85-100. https://doi.org/10.1016/0969-806X(93)90045-V

48. Czeremuszkin G, Latrèche M, Wertheimer MR, Silva Sobrinho AS. Ultrathin silicon-compound barrier coatings for polymeric packaging materials: an industrial perspective. Plasmas and Polymers. 2001;6(1-2):107-20. https://doi.org/10.1023/A:1011308919705

49. Garcia-Ayuso G, Vázquez L, Martínez-Duart JM. Atomic force microscopy (AFM) morphological surface characterization of transparent gas barrier coatings on plastic films. Surf Coat Tech. 1996;80(1-2):203-6. https://doi.org/10.1016/0257-8972(95)02712-2

50. Henry BM, Dinelli F, Zhao K-Y, Grovenor CRM, Kolosov OV, Briggs GAD, et al. A microstructural study of transparent metal oxide gas barrier films. Thin Solid Films. 1999;355-356:500-5. https://doi.org/10.1016/S0040-6090(99)00461-7

51. Plog S, Schneider J, Walker M, Schulz A, Stroth U. Investigations of plasma polymerized SiOx barrier films for polymer food packaging. Surf Coat Technol. 2011;205(2 Suppl):S165-70. https://doi.org/10.1016/j.surfcoat.2011.01.034

52. Moosheimer U, Bichler C. Plasma pretreatment of polymer films as a key issue for high barrier food packagings. Surf Coat Technol 1999;116-119:812-9. https://doi.org/10.1016/S0257-8972(99)00137-1

53. Alonso F, Ugarte JJ, Sansom D, Viviente JL, Oñate Jl. Effects of ion implantation on Ti-6Al-4V on its frictional behaviour against UHMWPE. Surf Coat Technol. 1996;83(1-3):301-6. https://doi.org/10.1016/0257-8972(96)02767-3

54. Lee EH. Ion beam modification of polyimides. In: Ghosh M, Mittal K, (Eds.). Polyimides: fundamental aspects and technologica applications. New York: Marcel Dekker; 1996

55. Toulemonde M, Trautmann C, Balanzat E, Hjort K, Weidinger A. Track formation and fabrication of nanostructures with MeV-ion beams. Nucl Instrum Meth B. 2004;216:1-8. https://doi.org/10.1016/j.nimb.2003.11.013

56. Betz N, Petersohn E, Le Moël A. Free radicals in swift heavy ion irradiated fluoropolymers: An electron spin resonance study. Radiat Phys Chem. 1996;47(3):411-4. https://doi.org/10.1016/0969-806X(95)00127-J

57. Dong H, Bell T. State-of-the-art overview. Ion beam surface modification of polymer towards improving tribological properties. Surface and Coating Technology. 1999;111(1):29-40. https://doi.org/10.1016/S0257-8972(98)00698-7

58. Pandiyara KN, Selvarajan V, Heeg J, Junge F, Lampka A, Barfels A, et al. Influence of bias voltage on diamond like carbon (DLC) film deposited on polyethylene terephthalate (PET) film surfaces using PECVD and its blood compatibility. Diamond Relat. Mater. 2010;19(7-9),1085-92. https://doi.org/10.1016/j.diamond.2010.03.016

59. Behar M, Fink D. Ion accelerators. In: Fink D. Fundamentals of ion-irradiated polymers. Berlin: Springer-Verlag; 2004.https://doi. org/10.1007/978-3-662-07326-1_2

60. Norgett MJ, Robinson MT, Torrens IM. A proposed method of calculating displacement dose rates. Nucl Eng Des. 1975;33(1):50-4 https://doi.org/10.1016/0029-5493(75)90035-7

61. Lee EH, Rao GR, Lewis MB, Mansur LK. Effects of electronic and recoil processes in polymers during ion implantation. J Mater Res. 1994;9(4):1043-50. https://doi.org/10.1557/JMR.1994.1043

62. Švorcík V, Rybka V, Hnatowicz V, Smetana Jr K. Structure and biocompatibility of ion beam modified polyethylene. J Mater Sci: Mater Med. 1997;8:435-40. https://doi.org/10.1023/A:1018509722748

63. Calcagno L, Compagnini G, Foti G. Structural modification of polymer films by ion irradiation. Nucl Instrum Meth B. 1992:65(1-4):41322. https://doi.org/10.1016/0168-583X(92)95077-5

64. Kofinas P, Cohen RE, Halasa AF. Gas permeability of polyethylene/poly(ethylene-propylene) semicrystalline diblock copolymers Polymer. 1994;35(6):1229-35. https://doi.org/10.1016/0032-3861(94)90016-7

65. Bracht H, Schneider S, Klug JN, Liao CY, Hansen JL, Haller EE, et al. Interstitial-Mediated diffusion in germanium under proton irradiation. Phys Rev Lett. 2009;103:255501. https://doi.org/10.1103/PhysRevLett.103.255501 
66. Sant'Ana PL, Prestes SMD, Mancini SD, Rangel RCC, Bortoleto JRR, Cruz NC, et al. Análise comparativa entre o grau de molhabilidade dos polímeros reciclados PVC e PET tratados por imersão ou deposição de filmes orgânicos em plasmas fluorados. Rev Bras Apl Vac. 2019;37(3):120-8. https://doi.org/10.17563/rbav.v37i3.1115

67. Sant'Ana PL, Bortoleto JRR, Cruz NC, Rangel EC, Durrant SF, Botti LMC, et al. Surface properties of pet polymer treated by plasma immersion techniques for food packaging. Int J Nano Rech. 2018;1(1):33-41.

68. Sant'Ana PL, Bortoleto JRR, Cruz NC, Rangel EC, Durrant SF, Botti LMC, et al. Surface properties and morphology of pet treated by plasma immersion ion implantation for food packaging. Nanomed Nanotechnol. 2018;3(3):000145. https://doi.org/10.23880/nnoa16000145

69. Sant'Ana PL. Polymers treated by plasma for optical devices and food packaging. Latvia: Scholar's Press; 2018.

70. Sant'Ana PL, Bortoleto JRR, Cruz NC, Rangel EC, Durrant SF. Study of wettability and optical transparency of pet polymer modified by plasma immersion techniques. Rev Bras Apl Vac. 2017;36(2):68-74. https://doi.org/10.17563/rbav.v36i2.1050 